\title{
On sea level change in the North Sea influenced by the North Atlantic Oscillation: local and remote steric effects
}

\author{
Xinping Chen ${ }^{\mathrm{a}, *}$, Sönke Dangendorf ${ }^{\mathrm{b}}$, Nikesh Narayan ${ }^{\mathrm{c}}$, Kieran O’Driscoll ${ }^{\mathrm{d}}$, \\ Michael N Tsimplis ${ }^{\mathrm{e}}$, Jian $\mathrm{Su}^{\mathrm{a}}$, Bernhard Mayer ${ }^{\mathrm{a}}$, Thomas Pohlmann ${ }^{\mathrm{a}}$ \\ ${ }^{a}$ Institute of Oceanography, Center for Marine and Climate Research, University of \\ Hamburg, Bundesstr. 53, 20146 Hamburg, Germany. \\ ${ }^{b}$ Research Institute for water and Environment, University of Siegen \\ ${ }^{c}$ Bundesamt für Seeschifffahrt und Hydrographie, Hamburg, Germany \\ ${ }^{d}$ Marine Research Group, School of Planning, Architecture \&3 Civil Engineering \\ (SPACE), Queen's University Belfast. \\ ${ }^{e}$ National Oceanography Centre, University of Southampton, SO14 3ZH.
}

\begin{abstract}
In this study, we investigated contributions of both local steric and remote baroclinic effects (i.e., steric variations external to the region of interest) to the inter-annual variability of winter sea level in the North Sea, with respect to the North Atlantic Oscillation (NAO), for the period of 1953-2010. On inter-annual time scales in this period, the NAO is significantly correlated to sea level variations in the North Sea only in the winter months (December-March), while its correlation to sea temperature over much of the North Sea is only significant in January and February. The discrepancy in sea level between observations and barotropic tide and surge models forced by tides and local atmospheric forcing, i.e., local atmospheric pressure effects and winds, in the present study are found to be consistent with pre-
\end{abstract}

\footnotetext{
*Corresponding author. Tel. +49 40428385753

Email address: xinping.chen@zmaw.de (Xinping Chen )
} 
vious studies. In the North Sea, local thermosteric effects caused by thermal expansion play a minor role on winter-mean NAO related sea level variability compared with NAO related atmospheric forcing. This is particularly true in the southeastern North Sea where water depths are mostly less than $25 \mathrm{~m}$. Our calculations demonstrate that the discrepancy can be mostly explained by remote baroclinic effects, which appear as water mass exchanges on the continental shelf and are therefore only apparent in ocean bottom pressure. In the North Sea, NAO related sea level variations are a hybrid of barotropic and baroclinic processes. Hence, they can only be adequately modelled with three-dimensional baroclinic ocean models with more realistic open boundary conditions (than barotropic models) that allow the exchange of heat and salt.

Keywords: North Sea, sea level, North Atlantic Oscillation, steric effect, baroclinic effect

\section{Introduction}

2 Global sea level rise is one of the possible effects of climate change (Harris 3 and Roach, 2007). Tide gauge records exhibit a global sea level rise of ap4 proximately $1.7 \mathrm{~mm} \mathrm{yr}^{-1}$ over the 20th century (Bindoff et al., 2007; Church 5 and White, 2011), and it is expected that this rise will continue through the 6 21st century as well, possibly at accelerated rates (Rahmstorf et al., 2007; 7 Slangen et al., 2012; Orlić and Pasarić, 2013). However, especially due to 8 oceanographic and meteorological forcing, the rates of rise are far from being 9 uniform, and display considerable temporal and spatial differences around 10 the globe (Church et al., 2004; Cazenave et al., 2008). The understanding of 
the driving mechanisms of sea level rise is therefore essential for evaluating past as well as possible future changes in regional sea level.

Sea level in the North Sea and especially in the German Bight has been extensively studied in the past decades (e.g., Langenberg et al., 1999; Wahl et al., 2011; Dangendorf et al., 2012). A review of sea level variations in the region since 1800 has been recently presented by Wahl et al. (2013). They estimated a sea level rise in the order of $1.7 \mathrm{~mm} \mathrm{yr}^{-1}$ since 1900 for the entire North Sea basin, but also pointed to significant spatial differences with increasing variability and trends along the coastlines from the English Channel to the southeastern sea, including the German Bight. It has been known that the possible contributions to sea level variations in the North Sea region include the following driving mechanisms: wind and atmospheric pressure anomalies through atmospheric loading; steric effects due to thermal/haline expansion or contraction associated with temperature and salinity changes; redistribution of volume associated with changes in ocean circulation; water mass exchange between land, oceans and atmosphere; and finally other processes such as land uplift caused by glacial isostatic adjustment. Although a full assessment of all possible contributions is still missing, Dangendorf et al. (2013) demonstrated that the majority of the intra- and inter-annual mean sea level variability can be explained by local atmospheric forcing, while on decadal time scales remotely forced steric variations become dominant.

In the past decades, there has been much effort on estimating the influence of internal climatic variability phenomena (e.g. ENSO, PDO, etc.) on regional sea level. In the Northeast Atlantic Ocean the dominant atmospheric mode is the North Atlantic Oscillation (NAO), hence in this study 
we focus on the NAO influence. The NAO significantly affects the climate of the North Atlantic and impacts many meteorological and oceanographic parameters, such as, wind, pressure, temperature and precipitation (Hurrell, 1995; Hurrell and Deser, 2009), and sea surface temperature (SST) (Becker, 1996; Dippner, 1997), especially during winter. Changes in each of these parameters may influence sea level variations in the North Sea via different baroclinic and barotropic adjustment processes.

Recent studies have demonstrated the impact of the NAO on sea level in the North Sea (Jevrejeva et al., 2005; Yan et al., 2004; Tsimplis and Shaw, 2008; Dangendorf et al., 2012). Woolf et al. (2003) have shown that a linear relationship between winter sea level anomalies and the NAO index can be used to explain most of the variability in the North Sea, the Mediterranean and the eastern parts of the North Atlantic, where sea level variations are also significantly correlated with the NAO on decadal time scales (Calafat et al., 2012). Wakelin et al. (2003) found a good relationship between sea level along western Europe coast and the NAO index in winter on inter-annual time scales, especially for the German Bight, where wind stress accounted for over $90 \%$ of the observed sea level variability during winter (Dangendorf et al., 2013). Wakelin et al. (2003) also estimated sea level changes per unit NAO over the northwest European continental shelf by considering results from a two-dimensional model driven by tides, local winds and atmospheric pressure, and they found that the NAO sensitivities from observations were, in general, higher than estimates from model results. This discrepancy might in part be caused by other contributions, such as temperature and rainfall which are also affected by the NAO, but were not included in their two-dimensional model. 
The latter was also confirmed by Tsimplis et al. (2005) in an overview about recent findings to the NAO influence on sea level over the Northern European Shelf. In a companion paper, Tsimplis et al. (2006) further examined the hypothesis that sea surface temperature could be responsible for the observed differences by estimating the sea level changes due to water thermal expansion near Den Helder in the shallow southern North Sea. Their results showed that the SST sensitivity to the NAO index near Den Helder is about $0.85^{\circ} \mathrm{C}$ per unit NAO in winter, which results in thermosteric sea level changes of about $10 \mathrm{~mm}$ per unit NAO, a value that could close the gap between observations and model results, if not considering model inaccuracy.

However, in addition to local contributions of temperature and salinity due to thermal expansion and haline contraction at regional scales, steric effects in one region can emerge from the local contribution, and also from remote steric signals produced further in other regions, since steric signals may travel from one area to adjacent areas. Moreover, redistribution of heat and salt (water mass) associated with processes including horizontal convergence and divergence of ocean circulation changes can also contribute to sea level variability as well (Fukumori and Wang, 2013). Therefore, deep water masses (e.g., the Atlantic Ocean) can be transferred to shallow shelf areas due to redistribution, and can finally contribute to local sea level changes along the coast. This contribution was discussed by Richter et al. (2012) for the Norwegian coast, where it plays a relatively important role for sea level changes in the period 1960-2010.

Since local contributions of temperature changes have not yet been further explored for the entire basin in the North Sea, the goal of the present study 
is to investigate how these affect inter-annual variability of sea level in the North Sea. Steric sea level variations forced external to the region are also estimated. We use a three-dimensional baroclinic shelf sea model to reanalyze the steric contribution over the entire basin during the period from 1953 to 2010 and compare the results with observations.

Previous studies have shown that correlation coefficients between sea level and the NAO index in the North Sea region are only significant from December to March (e.g., Wakelin et al., 2003; Dangendorf et al., 2012). The analysis in this study further shows that, only in January and February (JF), correlations between SSTs and the corresponding NAO index are significant most parts of the North Sea, while for December and March, the correlations are mostly insignificant (see section 3.2). Therefore, all analyses in this study focus on the winter variability on inter-annual time scales, i.e. we form winter means by only considering the months of January and February $(\mathrm{JF})$. This was consistently done for temperature and salinity as well as sea level values. Hence, in the following text, 'winter-mean' refers to the average for the two months (JF) unless stated otherwise.

The paper is structured as follows. Data and methods are described in section 2, which also includes model descriptions and model validation. The corresponding results and discussion are presented in section 3. Finally, conclusions are drawn in section 4 .

\section{Data and methods}

In this study, both observed and modeled temperature and sea level data were used. Details of these data are presented in sections 2.3-2.4. Model de- 
scription and validation are shown in section 2.1. The methods are presented in section 2.5.

\subsection{Utilized numerical model}

All simulated data mentioned within this article were produced with the numerical HAMburg Shelf Ocean Model (HAMSOM). It is a 3D baroclinic ocean circulation model solving the shallow water equations based on a semiimplicit scheme on the Arakawa-C grid. The HAMSOM coding excludes any time-splitting, i.e., free surface and internal baroclinic modes are always directly coupled. Terms that most severely limit the model time-step are formulated implicitly, such as vertical shear stress, diffusion terms and terms determining surface gravity waves, i.e., barotropic pressure and the vertically integrated continuity equation. Moreover, the Coriolis term is solved in a second-order accuracy in time, by means of a rotational matrix (Backhaus, 1985). For the horizontal turbulent diffusion, the exchange coefficient is calculated, according to Smagorinsky (1963) proportional to the sum of the horizontal shear of the horizontal velocity components and their linear strain rate. The vertical eddy viscosity was determined following Kochergin (1987), where it is increased with increasing vertical shear and decreased with increasing stability. For the bottom friction, the quadratic bottom stress is introduced in a semi-implicit way. Detailed information about HAMSOM can be found in Backhaus (1985) and Pohlmann (1996, 2006).

At the lateral open boundaries, a radiation treatment according to (Orlanski, 1976) and an additional relaxation term under inflow conditions is applied to allow water, which just left the model domain, to return with its corresponding properties. Details of the treatment in HAMSOM can be 
found in Chen et al. (2013).

A full 3D baroclinic simulation for the years 1953-2010 was performed in this study to provide temperature, salinity and sea level model results for further analyses. The model domain covers the entire North Sea (Fig. 1) with horizontal resolution of $1.5^{\prime}$ latitude $\times 2.5^{\prime}$ longitude (less than $3 \mathrm{~km}$ in both horizontal directions) and with 30 vertical z-layers of gradually increasing thicknesses from $5 \mathrm{~m}$ within the upper $50 \mathrm{~m}$ to $50 \mathrm{~m}$ below $200 \mathrm{~m}$ depth. The time-step was five minutes, and a spin-up time of 5 years was used for the model simulation.

Atmospheric forcing data were provided by the global NCEP/NCAR atmospheric reanalysis data (Kalnay et al., 1996; Kistler et al., 2001), where six-hourly values have been interpolated into the model grid and time-step. The data were used previously by O'Driscoll et al. (2013) for the North Sea model. The authors pointed out that the large-scale structure of the temperature patterns were reasonably reproduced.

The lateral open boundary forcing for the North Sea model was provided by an intermediate HAMSOM version covering the North-West European Shelf (NWES). The domain of the NWES model extends over the continental shelf from $47^{\circ} 41^{\prime} \mathrm{N}$ to $63^{\circ} 53^{\prime} \mathrm{N}$ and $15^{\circ} 5^{\prime} \mathrm{W}$ to $13^{\circ} 55^{\prime} \mathrm{E}$ (Fig. 1). The horizontal resolution is $12^{\prime}$ in latitude and $20^{\prime}$ in longitude $(\sim 20 \mathrm{~km})$. In the vertical, in agreement with the North Sea model, a number of 30 layers was employed as follows: $10 \mathrm{~m}$ surface layer; $10 \times 5 \mathrm{~m}$ layers $10-60 \mathrm{~m} ; 10 \times 10 \mathrm{~m}$ layers $60-160 \mathrm{~m} ; 40 \mathrm{~m}$ layers $160-200 \mathrm{~m} ; 2 \times 100 \mathrm{~m}$ layers $200-400 \mathrm{~m} ; 150 \mathrm{~m}$ layer 400-550 m; $250 \mathrm{~m}$ layer 550-800 m; $400 \mathrm{~m}$ layer 800-1200 m; $2 \times 500 \mathrm{~m}$ layers $1200-2200 \mathrm{~m}$; $600 \mathrm{~m}$ layer 2200-2800 m; $700 \mathrm{~m}$ layer $2800-3500 \mathrm{~m}$. 
The NWES model used the same atmospheric forcing data as the North Sea model. At the lateral open boundaries, except at the eastern boundary of the NWES model to the Baltic Sea, monthly temperature, salinity and sea surface elevation were provided by GECCO2 (see Köhl et al. (2012) for details). Ocean tides (11 tidal constituents: M2, S2, O1, K1, Q1, P1, N2, K2, M4, MS4, MN4) were included at the lateral boundaries in both the NWES and the North Sea models. At the eastern lateral boundary of the NWES model, we followed the treatment in Mathis et al. (2013): in order to assure for the appropriate magnitude and variability of Baltic outflow, volume fluxes are directly prescribed at the boundary, which is the normal procedure for grid cells in the HAMSOM representing river input cells; the volume fluxes (i.e., the inflow from the Baltic Sea) during 1953-2010 were reconstructed by means of the river runoff data from the studies of Meier and Kauker (2003) and Kronsell and Andersson (2012), of which seasonal cycles and annual means for each year were kept in the present study; the Baltic outflow salinity is described by monthly climatologies from World Ocean Atlas 20019 (WOA09) (Antonov et al., 2010).

In addition to the 3D baroclinic model simulation, another hindcast with the North Sea model in barotropic mode was performed for the period 1953-2010. The barotropic model was forced by wind, atmospheric pressure and tides (hereafter referred to tide + surge model). At the sea surface and along the open boundary, the meteorological influence is estimated from sea level pressure (SLP) values using the inverse barometric correction. Similar to the baroclinic model, the lateral open boundary conditions for the North Sea model were also provided by the corresponding barotropic 
tide+surge version of the NWES model which contains the interaction of tides and surges. The interaction is thus included at the open boundaries of the North Sea model as well, which is important at the shallow southern boundary (e.g., the English Channel boundary). The 11 dominant tidal constituents and atmospheric forcing data were the same as those used in the baroclinic model.

\section{2. model validation}

Simulated model results were validated with observations, by applying correlation coefficient and model skill. Following Willmott (1981), the skill is defined as

$$
W S=1-\frac{\sum\left(X_{\text {model }}-X_{o b s}\right)^{2}}{\sum\left(\left|X_{\text {model }}-\overline{X_{o b s}}\right|+\left|X_{o b s}-\overline{X_{o b s}}\right|\right)^{2}},
$$

where $X_{\text {model }}$ and $X_{\text {obs }}$ represent the respective model results and observations, and $\overline{X_{o b s}}$ is the mean value of observations. The highest value, $W S=1$, indicates a perfect agreement between model and observation, while skill score equal to zero means complete disagreement. Note that only the validation for the winter months is presented here. For more complex validations the interested reader is referred to $\mathrm{Su}$ et al. (2014).

The validation results for different locations are shown in Fig. 2. Obviously, the modelled temperature and sea level variations fit well to the observations at Helgoland and Den Helder (details of these observed data are introduced in the following section 2.3), which is expressed by correlations always beyond 0.94 and skill values, WS, larger than 0.96 (up and middle panels in Fig. 2). 
In addition, BSH SST observations (which were kindly provided by the BSH, the German Federal Maritime and Hydrographic Agency) are used for model validation. These BSH SSTs are based on both satellite and ship observations, and were processed and gridded by the BSH satellite data service (http: //www.bsh.de/aktdat/mk/MethodenE.html). The data cover the North Sea for the period of 1969-2008, with a horizontal resolution of $(1 / 3)^{\circ}$ latitude and of approximately $(2 / 3)^{\circ}$ longitude. It can be seen from Fig. 2 (bottom; left) that the correlation of domain-averaged SSTs between modelled and observed reaches up to 0.97 , and the skill, $W S$, is 0.98 .

Fig. 2 (bottom; right) shows the correlation coefficients and skill scores $(W S)$ of winter-mean sea level between model results and tide gauge observations (introduced in the following section 2.3. Both the correlations and the skill scores, $W S$, are relatively high at most of the locations in the North Sea. The correlations and skill scores, $W S$, for the sea level off the coast of Denmark and Germany are considerably high $(>0.9)$, whereas at the other locations in the North Sea they are a little smaller but still high, reaching mostly 0.9 .

Overall, we find a reasonable agreement between observations and model results, which permits the application of the model results for further analyses.

\subsection{Temperature, salinity and sea level data}

Modelled temperature and salinity data for the years 1953-2010 were obtained from the 3D baroclinic simulation introduced above. Monthly insitu temperature and salinity measurements collected from a station located at Helgoland in the German Bight (Fig. 1) were analyzed. Details of these 
data have been described in Wiltshire and Manly (2004) and Franke et al. (2004). The data have been available since 1873, however, for consistency with model set-up and observed sea level, only data from 1953 onwards were used in this study.

Modelled sea level data were taken from the 3D baroclinic and the barotropic model results, while observed sea level data from different tide gauges were acquired from the Permanent Service for Mean Sea Level (Woodworth and Player, 2003). Only data from the tide gauges providing at least 20 years of data were considered in this study to assure comparability of results, especially for correlation and linear trend analyses. There were 22 such tide gauges available for the North Sea, of which the locations are shown in Fig. 1. We further analyzed one additional record from the Helgoland tide gauge covering the period from 1953 to 2008. This record was reconstructed by Wahl et al. $(2010,2011)$ on the basis of a combination of observed high and low water levels as well as hourly observations, which represents a reasonable supplement to the temperature and salinity observations in that area.

\subsection{NAO data}

To be consistent with previous studies of Wakelin et al. (2003) and Tsimplis et al. (2006), the NAO index data used in the present study was downloaded from the website of the Climatic Research Unit, University of East Anglia (http://www.cru.uea.ac.uk/cru/data/nao/nao.dat). This index was computed by taking differences between SLP anomalies over Gibraltar and southwest Iceland (Jones et al., 1997). 


\subsection{Methods}

To investigate the local contribution of steric effects to sea level changes in the North Sea, we computed the local steric sea level in this study. As a first step, we converted the temperature and salinity anomalies in terms of density anomalies using the equation of state of the ocean. The local steric sea level is thus calculated by means of density anomalies at each grid point according to:

$$
S L_{\text {steric }}(x, y, t)=\int_{-H}^{0} \frac{\rho_{0}(x, y, z)-\rho(x, y, z, t)}{\rho_{0}(x, y, z)} d z,
$$

where $\rho_{0}(x, y, z)$ is the reference density and $H$ the water depth. $\rho(x, y, z, t)$ is estimated based on the full equation of state, which is a non-linear function of temperature, salinity and pressure. $S L_{\text {steric }}$ can be further separated into a thermosteric and a halosteric part by replacing either the time-varying salinity or temperature by their time mean values that are also used for calculating the reference density, i.e., $\rho_{0}(x, y, z)$. For example, for calculating thermosteric sea level (hereafter $S L_{\text {ThermoS }}$ ), at each model grid point of the North Sea model, salinity values from the 3D model results were temporally and vertically averaged over the study period to obtain the climatological salinity filed.

In particular, we calculated winter-mean $S L_{\text {ThermoS }}$ anomalies at Helgoland and at Den Helder (see Fig. 1) by means of both observed and simulated sea temperatures, assuming the salinity to be constant at the average winter-mean value (32.57 psu at Helgoland and 28.27 at Den Helder) computed from the observed salinity values. We notice that during winter the water column is well mixed in shallow waters of the North Sea, especially in 
the German Bight and in the southern North Sea. Hence, the temperature change near the surface can be used to represent variation over the whole column. Thus, the $S L_{\text {ThermoS }}$ at Helgoland (at Den Helder) was assessed for a nominal depth of $20 \mathrm{~m}(18 \mathrm{~m})$ corresponding to the model depth.

To evaluate the relationship between the NAO and sea level/temperature, the winter-mean time series of sea level/temperature anomalies are correlated with the corresponding winter-mean NAO time series (both detrended). Moreover, following the approach proposed by Wakelin et al. (2003), the sensitivity of winter-mean sea level/temperature to the corresponding wintermean NAO index is estimated with linear regression models between sea level/temperature and the corresponding NAO time series, assuming that sea level/temperature is a linear function of the NAO index.

\section{Results and discussion}

\subsection{Wind and atmospheric pressure effects on sea level changes}

In order to show the NAO influence on sea level changes in the North Sea, the correlation coefficients between the winter-mean sea level from the barotropic tide+surge model (hereafter referred to $S L_{t+s}$ ) and the NAO index were calculated. It is shown that the correlations are statistically significant over much of the North Sea for the period of 1953-2010 (Fig. 3(a)). Strong correlations occur in the north and east of the region, while relatively weak correlations appear off the eastern British coast, especially at the southern entrance to the North Sea through the English Channel.

To show the relative importance of winds and SLP on sea level changes in the North Sea, we performed another model simulation forced only by 
wind and tides, not considering the inverted barometer effect induced by SLP. By comparison of Fig. 3(a) and (b), we can see that, regarding the relationship between winter-mean sea level and the NAO index, SLP has significant influences in the northern and central North Sea, extending from east of the Sheltland shelf southward to the Southern Bight. By contrast, in the region off the coast of Denmark, Germany, and the Netherlands, as well as in the area around the north and east coasts of Scotland and in the Norwegian Trench area, the influence of SLP is minor, indicating that the wind plays a more important role in these regions. Our results are consistent with previous studies (e.g., Wakelin et al., 2003; Woolf et al., 2003).

The spatial distribution of the sensitivities of winter-mean $S L_{t+s}$ to the NAO index (Fig. 3(c)) is not homogeneous showing amplitudes of less than $10 \mathrm{~mm}$ per unit NAO along the English coastal region to over $80 \mathrm{~mm}$ per unit NAO in the German Bight. Furthermore, both the correlations and sensitivities of winter-mean $S L_{t+s}$ related to the NAO index are in relatively good agreement with those of tide gauge observations (Fig. 4) over the period considered: the average of the difference of the correlations (sensitivities) to the NAO index between $S L_{t+s}$ and observations is 0.085 (5.4), which is $\sim 18 \%$ (15\%) of the average of the correlations (sensitivities) of observations, being 0.47 (36.7). However, it can be seen from Fig. 4 (black curves) that winter-mean $S L_{t+s}$ exhibits higher correlations and lower sensitivities related to the NAO index compared with those of observations, especially in the German Bight and off the coast of Denmark. For instance, at Helgoland, the correlation and the sensitivity of the observed sea level are, respectively, 0.66 and $72 \mathrm{~mm}$ per unit, while that of the sea level from the tide+surge model is 
respective 0.71 and $64 \mathrm{~mm}$ per unit NAO index (Table 1). This discrepancy was previously noted by Wakelin et al. (2003), where a coarser resolution model was employed. To explain this discrepancy, contributions from both local steric effects and remote forcing to sea level changes are investigated in the following sections.

\subsection{Local contributions of steric effects on sea level changes}

Before investigating steric effects on sea level changes, first of all we show the relationship between SSTs and the NAO index in the North Sea. Fig. 5 presents correlation coefficients between SSTs and the NAO index in the four months (December-March) for the period of 1953-2010. It can be seen that, only in January and February, the correlations are significant over most parts of the North Sea. December and March, however, seem to represent a kind of transition to the bounded seasons, in which the correlations are statistically insignificant. Moreover, correlations for the other months are also insignificant over most area of the North Sea (not shown). Therefore, in the present study we focus on the variability of winter-mean (JF) time series of temperature, and also of sea level for consistency.

At Helgoland located in the German Bight, winter-mean temperature anomalies reach up to $3.5^{\circ} \mathrm{C}$ (Fig. $6(\mathrm{~A})$ ), leading to a high correlation with the winter-mean NAO index (correlation coefficient is 0.63); temperature sensitivity to the corresponding winter-mean NAO index is $0.49^{\circ} \mathrm{C}$ per unit NAO (Table 1). Similarly, at Den Helder located in the southern North Sea, winter-mean temperature anomalies are extremely high $\left(>4.0^{\circ} \mathrm{C}\right)$ such as in 1963 (Fig. 6(a)); the correlation coefficient between the winter-mean temperature and the NAO index is 0.75 , which results in SST sensitivity to 
the NAO index of about $0.61^{\circ} \mathrm{C}$ per unit NAO (Table 1 ).

The local contribution of steric effects is estimated in the North Sea, by means of Eq. 2. Fig. 6(C and D) shows the comparison of time series of observed sea level, barotropic $S L_{t+s}$, and calculated local thermosteric sea level $\left(S L_{\text {ThermoS }}\right)$ and halosteric sea level anomalies at Helgoland. The figure demonstrates that sea level variations due to local thermosteric effects are limited, accounting to only on the order of $5.0 \mathrm{~mm}$, which is rather small compared with the $S L_{t+s}$ or observed sea level changes (up to $400 \mathrm{~mm}$ at Helgoland). The sensitivity of winter-mean $S L_{\text {ThermoS }}$ to the NAO index is only about $1.0 \mathrm{~mm}$ per unit, which is much smaller than that of the observed sea level (72 mm per unit), and also lower than that of $S L_{t+s}(64 \mathrm{~mm}$ per unit in Table 1). Similarly, at Den Helder, sea level values due to local thermosteric effects are much smaller than those of $S L_{t+s}$ or observed sea level (Fig. 6(b-c)); sensitivity of winter-mean $S L_{\text {ThermoS }}$ to the NAO index is only $1.0 \mathrm{~mm}$ per unit (Table 1). It is thus evident that this difference between the sensitivity of winter $S L_{t+s}$ and observed sea level in the German Bight cannot be caused solely by the local thermosteric contribution.

Salinity anomalies at Helgoland are up to 2.0 psu (Fig. 6(B)), which can induce local sea level anomalies on the order of $30 \mathrm{~mm}$. This demonstrates that sea level anomalies caused by local halosteric effects are considerably larger than those caused by thermosteric effects at Helgoland (Fig. 6(C)), indicating that local halosteric effects contribute most of the total steric change in freshwater influenced areas like the German Bight. However, the correlation between the winter-mean salinity anomalies and the NAO index is only -0.17 , which is not statistically significant at the $95 \%$ significance level. 
Therefore, we do not further analyze the relation between local salinity and the NAO in this study.

For the entire North Sea, the sensitivity of the winter-mean $S L_{\text {ThermoS }}$, based on the simulated temperatures, to the NAO index is almost everywhere less than $3 \mathrm{~mm}$ per unit NAO index, with an exception near the Norwegian coast, where maximum sensitivity is over $5 \mathrm{~mm}$ per unit (Fig. 7a). Moreover, at the coastal tide gauge stations the effects of thermal expansion in winter on the correlation and sensitivity related to the NAO index are quite small (Fig. 4b in red). With the exception of the deep waters of the Norwegian Trench, the percentage of the sensitivity of $S L_{T h e r m o S}$ to $S L_{t+s}$ is small over most parts of the basin (not shown). In the central and northwestern North Sea, the percentage can reach $10 \%$. In the area of around Dogger Bank and the coastal areas of the Netherlands, Germany and Denmark, the percentage is about $2 \%$, while maximum values in the North Sea are found near the coast of Norway. On average over the North Sea, the sensitivity of the $S L_{T h e r m o S}$ accounts for approximately $5 \%$ compared to the $S L_{t+s}$.

Tsimplis et al. (2006) also estimated sea level change due to the local contribution of thermosteric effects at Den Helder. Their results showed that the sensitivity of $S L_{\text {ThermoS }}$ can be as much as $10 \mathrm{~mm}$ per unit NAO index, which is over $20 \%$ to the sensitivity of the observed sea level $(55 \mathrm{~mm}$ per unit NAO index (see Table 1 of Tsimplis et al. (2006)). However, by recalculating the sensitivity at Den Helder we found that the value provided by Tsimplis et al. (2006) was flawed (i.e., $0.08 \mathrm{~cm} \mathrm{~m}^{-1}$ per unit in their Table 1). In contrast, the calculation in this study suggests that the sensitivity of the $S L_{\text {ThermoS }}$ to the NAO is only on the order of $1.0 \mathrm{~mm}$ per unit (see 
Table 1). Therefore, we arrive at the conclusion that the local contribution of thermosteric effects cannot explain the discrepancy in the NAO sensitivity between tide + surge modelled and observed data in shallow areas of the North Sea.

3.3. Contributions of remote forcing: baroclinic effects and large-scale atmospheric forcing

Two processes are not accounted for in the barotropic model, but included in the 3D baroclinic model. One is the process of baroclinic density-driven redistribution of water mass associated with temperature and salinity changes. The other one is the large-scale wind forcing (LSWF) and the associated circulation external to the NWES model domain, which are not considered at the open boundary of the barotropic model, but are introduced in the 3D model by the open boundary conditions provided by the global GECCO2 data. This external contribution consists of baroclinic as well as barotropic effects. As demonstrated by Calafat et al. (2012), much of the decadal sea level variability in the eastern north Atlantic can be explained by coastally trapped waves which are driven by longshore winds that are directly connected to the NAO. Dangendorf et al. (under review) argued that these waves may also propagate into the North Sea and they are primarily steric (and therefore baroclinic) in nature. This reflects one advantage of the 3D model with respect of open boundary conditions. In the present study, these two processes are not separately considered, since they are coupled together. These two contributions missing in the barotropic model but additionally considered in the 3D baroclinic model are referred to the baroclinic + LSWF contributions in the following text. 
Fig. 4 exhibits that, at most tide gauge locations in the North Sea, both correlations and sensitivities of 3D modelled sea level (hereafter $S L_{3 D}$ ) to the winter-mean NAO index are closer to those of observations than those of the $S L_{t+s}$. At the considered locations, the average of the difference of the correlations/sensitivities between $S L_{t+s}$ and the observed sea level (Fig. 4 in black) is $0.085 / 5.4$, while the average of the difference of those between $S L_{3 D}$ and observations (Fig. 4 in blue) is dropped to $0.050 / 3.4$.

The discrepancy in sea level sensitivity between observed and tide + surge modelled values can be much stronger decreased by the baroclinic + LSWF contributions than by local steric effects. For example, at Helgoland, the sensitivity of winter-mean tide gauge sea level (black line in Fig. 6(D)) is $72 \mathrm{~mm}$ per unit, while that of $S L_{t+s}$ (black dashed line in Fig. 6(D)) is 64 $\mathrm{mm}$ per unit (see Table 1). As expected, a higher sensitivity is found for the winter-mean $S L_{3 D}$ (blue line in Fig. 6(D)), being $70 \mathrm{~mm}$ per unit (Table 1). Therefore, the baroclinic $+\mathrm{LSWF}$ effect in the $3 \mathrm{D}$ baroclinic model contributes $\sim 6 \mathrm{~mm}$ per unit, whereas $S L_{\text {ThermoS }}$ provides only $1 \mathrm{~mm}$ per unit NAO in sea level sensitivity. Similarly, for Den Helder station, we can see from Fig. 6(c) and Table 1 that the additional contribution of the 3D baroclinic model to sea level sensitivity is about $7 \mathrm{~mm}$ per unit NAO, which can close the gap of sensitivity between observed sea level (51 mm per unit) and $S L_{t+s}$ (40 mm per unit) significantly more than the sensitivity of $S L_{T h e r m o S}$, which is only $\sim 1.0 \mathrm{~mm}$ per unit NAO.

Fig. 7(a) shows the sensitivity of $S L_{\text {ThermoS }}$ calculated by Eq. 2 . It is clear that the sensitivity of $S L_{\text {ThermoS }}$ generally follows the ocean bottom topography in the region: it is very low in the shallow areas such as off the 
coast of the Netherlands, Germany and Denmark as well as off the east coast of the UK, while it is larger in the northern North Sea, especially in the Norwegian Trench, where water depths reach $700 \mathrm{~m}$. This could be expected, since due to the shallow water depths most parts of the North Sea water body are not able to produce any significant steric signal (Woodworth et al., 2007; Dangendorf et al., under review). This can also explain why at the tide gauge locations in the North Sea, which are situated in very shallow water, variability in local steric sea level is very small.

However, this does not mean that steric effects are completely negligible in the North Sea region. It rather suggests that steric signals in deep water are indeed transferred to shallow coastal areas, and appear as mass signals along the coast Bingham and Hughes (2012). This effect becomes clear when looking at Fig. 7(b). Here, differences between the baroclinic and the barotropic model runs are displayed $\left(S L_{3 D}\right.$ minus $\left.S L_{t+s}\right)$. The additional contribution introduced by the baroclinic model accounts for up to $12 \mathrm{~mm}$ per unit NAO. A lack of the sensitivity in the northern North Sea, while largest sensitivities are found in the Norwegian Trench area, where values are $\sim 6-12 \mathrm{~mm}$ per unit NAO. Along the southeastern coastlines positive sensitivities in the order of $\sim 4-7 \mathrm{~mm}$ per unit NAO are found; values that can minimize the gap between observations and barotropic models. This water mass redistribution likely explains why sensitivies in the baroclinic model are better represented than in the barotropic tide+surge model.

Finally, we point out that, even though sensitivities of $S L_{3 D}$ to the NAO index are much closer to those of observations, compared with those of barotropic modelled sea level, they still show slightly smaller values than 
those of observations (Fig. 4 in blue). This might be due to model inaccuracies and/or still missing processes in the 3D model. Such missing processes, for instance, might be related to inadequate approximations of the river runoff, which is only considered on a mean climatological basis in this study. It has been reported that the precipitation over the North Sea is also correlated to the NAO index (Hurrell, 1995).

\section{Summary and conclusions}

The NAO strongly affects inter-annual to decadal North Sea sea level variability in winter, except for the region off the English coast in the southern North Sea. Here we have investigated the role of NAO related atmospheric forcing on sea level changes in the North Sea by means of the barotropic tide+surge model. The sensitivity of $S L_{t+s}$ to the winter-mean NAO index is less than $10 \mathrm{~mm}$ per unit NAO along the English coastal region, while is greater than $80 \mathrm{~mm}$ per unit NAO in the German Bight. In agreement with previous studies (e.g. Wakelin et al., 2003), our model results also show that winter-mean $S L_{t+s}$ exhibits a slightly smaller sensitivity to the NAO index compared to observations, especially in the German Bight and off the coast of Denmark. For instance, at Helgoland/Den Helder, the sensitivity of the observed sea level is $72 / 51 \mathrm{~mm}$ per unit, while that of the sea level from the tide + surge model is $64 / 40 \mathrm{~mm}$ per unit NAO index.

With the help of Tsimplis, a wrong conclusion was found in Tsimplis et al. (2006), who suggested that local thermosteric variations may explain the gap between observations and barotropic models. Our calculations point to a negligible role of local thermosteric sea level in terms of NAO related 
atmospheric forcing in winter. This is to be expected since the North Sea depths are too low to produce a significant sea level signal, particularly true in the southeastern North Sea, where the water depths are generally less than $25 \mathrm{~m}$. We found that the unexplained contribution in the barotropic tide + surge model can be mostly assigned to remote forcing, i.e., steric variations triggered external to the region and the large-scale wind forcing. These variations appear as mass changes on the continental shelf and are therefore only visible in the ocean bottom pressure signal. This in turn confirms recent results from Calafat et al. (2012, 2013) and Dangendorf et al. (under review), who attributed decadal sea level changes in the North Sea basin to coastally trapped Kelvin waves forced by longshore winds along the eastern boundary of the Northeast Atlantic. Our results demonstrate that NAO related sea level variations are a hybrid of barotropic and baroclinic processes, which are to a large extend driven by variations in the large-scale wind fields. Hence, NAO related sea level changes can be more adequately modelled with 3D baroclinic ocean models rather than 2D ocean models, which have (i) high resolution, and (ii) more realistic boundary conditions allowing for the exchange of heat and salt and the forcing of large-scale wind field external to the domain of interest. Finally, we note that more detailed investigations on the mechanisms of steric redistribution in the North Atlantic and its marginal seas are required to derive reliable regional sea level projections.

\section{Acknowledgements}

This work was conducted in the frame of the BMBF-project "Nordatlantik", the EU-MarinERA-project "ECODRIVE", and the CliSAP-project 
${ }_{525}$ Hamburg-2K. The authors would like to thank Armin Köhl for providing the ${ }_{526}$ GECCO2 data. We are grateful to Hendrik van Aken for providing the mean ${ }_{527}$ monthly values for temperature at Marsdiep (Den Helder). 


\section{References}

Antonov, J., Seidov, D., Boyer, T., Locarnini, R., Mishonov, A., Garcia, H., Baranova, O., Zweng, M., Johnson, D., 2010. World Ocean Atlas 2009, Volume 2: Salinity. S. Levitus, Ed. NOAA Atlas NESDIS 69.

Backhaus, J., 1985. A three-dimensional model for the simulation of shelf sea dynamics. Ocean Dyn. 38 (4), 165-187.

Becker, G., 1996. Sea surface temperature changes in the North Sea and their causes. ICES J. Mar. Sci.: Journal du Conseil 53 (6), 887-898.

Bindoff, N., Willebrand, J., Artale, V., Cazenave, A., Gregory, J., Gulev, S., Hanawa, K., Le Quéré, C., Levitus, S., Nojiri, Y., et al., 2007. Observations: oceanic climate and sea level. In: Climate change 2007: The physical Science Basis. Contribution of Working Group I to the Fourth Assessment report of the Intergouvernmental Panel on Climate Change. Cambridge University Press, Cambridge, UK, and New York, USA., 2007, $385-432$.

Bingham, R., Hughes, C., 2012. Local diagnostics to estimate density-induced sea level variations over topography and along coastlines. J. Geophys. Res.: Oceans (1978-2012) 117 (C1).

Calafat, F., Chambers, D., Tsimplis, M., 2012. Mechanisms of decadal sea level variability in the eastern North Atlantic and the Mediterranean Sea. J. Geophys. Res.: Oceans (1978-2012) 117 (C9).

Calafat, F., Chambers, D., Tsimplis, M., 2013. Inter-annual to decadal sealevel variability in the coastal zones of the norwegian and siberian seas: 
The role of atmospheric forcing. J. Geophys. Res.: Oceans 118 (3), 12871301.

Cazenave, A., Lombard, A., Llovel, W., 2008. Present-day sea level rise: A synthesis. C.R. Geosci. 340 (11), 761-770.

Chen, X., Liu, C., OâĂŹDriscoll, K., Mayer, B., Su, J., Pohlmann, T., 2013. On the nudging terms at open boundaries in regional ocean models. Ocean Modelling 66, 14-25.

Church, J. A., White, N. J., 2011. Sea-level rise from the late 19th to the early 21st century. Surv. Geophys. 32 (4), 585-602.

Church, J. A., White, N. J., Coleman, R., Lambeck, K., Mitrovica, J. X., 2004. Estimates of the regional distribution of sea level rise over the 19502000 period. J. Clim. 17 (13), 2609-2625.

Dangendorf, S., Calafat, F., Arns, A., Wahl, T., Haigh, I., Jensen, J., under review. Mean Sea Level variability in the North Sea: processes and implications. J. Geophys. Res.: Oceans (submitted in Feb. 2014).

Dangendorf, S., Mudersbach, C., Wahl, T., Jensen, J., 2013. Characteristics of intra-, inter-annual and decadal sea-level variability and the role of meteorological forcing: the long record of Cuxhaven. Ocean Dyn. 63 (2-3), 209-224.

Dangendorf, S., Wahl, T., Hein, H., Jensen, J., Mai, S., Mudersbach, C., 2012. Mean Sea Level Variability and Influence of the North Atlantic Oscillation on Long-Term Trends in the German Bight. Water 4 (1), 170-195. 
Dippner, J., 1997. SST anomalies in the North Sea in relation to the North Atlantic Oscillation and the influence on the theoretical spawning time of fish. Ocean Dyn. 49 (2), 267-275.

Franke, H.-D., Buchholz, F., Wiltshire, K. H., 2004. Ecological long-term research at Helgoland (German Bight, North Sea): retrospect and prospectan introduction. Helgoland Mar. Res. 58 (4), 223-229.

Fukumori, I., Wang, O., 2013. Origins of heat and freshwater anomalies underlying regional decadal sea level trends. Geophys. Res. Lett.

Harris, J. M., Roach, B., 2007. The economics of global climate change. Global Development And Environment Institute Tufts University.

Hurrell, J., 1995. Decadal trends in the North Atlantic Oscillation: regional temperatures and precipitation. Science 269 (5224), 676-679.

Hurrell, J. W., Deser, C., 2009. North Atlantic climate variability: the role of the North Atlantic Oscillation. J. Mar. Syst. 78 (1), 28-41.

Jevrejeva, S., Moore, J., Woodworth, P., Grinsted, A., 2005. Influence of large-scale atmospheric circulation on European sea level: results based on the wavelet transform method. Tellus A 57 (2), 183-193.

Jones, P., Jonsson, T., Wheeler, D., 1997. Extension to the North Atlantic Oscillation using early instrumental pressure observations from Gibraltar and south-west Iceland. Int. J. Climatol. 17 (13), 1433-1450.

Kalnay, E., Kanamitsu, M., Kistler, R., Collins, W., Deaven, D., Gandin, L., Iredell, M., Saha, S., White, G., Woollen, J., et al., 1996. The 
NCEP/NCAR 40-year reanalysis project. Bull. Am. Meteorol. Soc. 77 (3), 437-471.

Kistler, R., Kalnay, E., Collins, W., Saha, S., White, G., Woollen, J., Chelliah, M., Ebisuzaki, W., Kanamitsu, M., Kousky, V., et al., 2001. The NCEP-NCAR 50-year reanalysis: Monthly means CD-ROM and documentation. Bull. Am. Meteorol. Soc. 82 (2), 247-268.

Kochergin, V., 1987. Three-dimensional prognostic models. Coast. Est. S. 4, 201-208.

Köhl, A., Siegismund, F., Stammer, D., 2012. Impact of assimilating bottom pressure anomalies from GRACE on ocean circulation estimates. J. Geophys. Res. 117 (C4), C04032.

Kronsell, J., Andersson, P., 2012. HELCOM Baltic Sea Environment Fact Sheet(s) 2012. Online. http://www.helcom.fi/baltic-seatrends/environment-fact-sheets/.

Langenberg, H., Pfizenmayer, A., Von Storch, H., Sündermann, J., 1999. Storm-related sea level variations along the North Sea coast: natural variability and anthropogenic change. Cont. Shelf Res. 19 (6), 821-842.

Mathis, M., Mayer, B., Pohlmann, T., 2013. An uncoupled dynamical downscaling for the North Sea: Method and evaluation. Ocean Modell. 72, 153166.

Meier, H., Kauker, F., 2003. Modeling decadal variability of the Baltic Sea: 2. Role of freshwater inflow and large-scale atmospheric circulation for salinity. J. Geophys. Res. 108 (C11). 
O’Driscoll, K., Mayer, B., Ilyina, T., Pohlmann, T., 2013. Modelling the cycling of persistent organic pollutants (POPs) in the North Sea system: fluxes, loading, seasonality, trends. J. Mar. Syst. 111/112, 69-82, doi:10.1016/j.jmarsys.2012.09.011.

Orlanski, I., 1976. A simple boundary condition for unbounded hyperbolic flows. J. Comput. Phys. 21 (3), 251-269.

Orlić, M., Pasarić, Z., 2013. Semi-empirical versus process-based sea-level projections for the twenty-first century. Nature Clim. Change.

Pohlmann, T., 1996. Calculating the annual cycle of the vertical eddy viscosity in the North Sea with a three-dimensional baroclinic shelf sea circulation model. Cont. Shelf Res. 16 (2), 147-161.

Pohlmann, T., 2006. A meso-scale model of the central and southern North Sea: Consequences of an improved resolution. Cont. Shelf Res. 26 (19), $2367-2385$.

Rahmstorf, S., Cazenave, A., Church, J. A., Hansen, J. E., Keeling, R. F., Parker, D. E., Somerville, R. C., 2007. Recent climate observations compared to projections. Science 316 (5825), 709-709.

Richter, K., Nilsen, J., Drange, H., 2012. Contributions to sea level variability along the Norwegian coast for 1960-2010. J. Geophys. Res.: Oceans (19782012) 117 (C5).

Slangen, A., Katsman, C., Van de Wal, R., Vermeersen, L., Riva, R., 2012. Towards regional projections of twenty-first century sea-level change based on IPCC SRES scenarios. Clim. Dyn. 38 (5-6), 1191-1209. 
Smagorinsky, J., 1963. General circulation experiments with the primitive equations: I. The basic experiment. Mon. Weather Rev. 91 (3), 99-164.

Su, J., Sein, D., Mathis, M., Mayer, B., O’Driscoll, K., Chen, X., Mikolajewicz, U., Pohlmann, T., 2014. Assessment of a zoomed global model for the North Sea by comparison with a conventional nested regional model. Tellus A 66, 23927, http://dx.doi.org/10.3402/tellusa.v66.23927.

Tsimplis, M., Shaw, A., 2008. The forcing of mean sea level variability around Europe. Global Planet. Change 63 (2), 196-202.

Tsimplis, M., Shaw, A., Flather, R., Woolf, D., 2006. The influence of the North Atlantic Oscillation on the sea-level around the northern European coasts reconsidered: the thermosteric effects. Philos. Trans. Roy. Soc. London Ser. A: Math. Phys. Eng. Sci. 364 (1841), 845-856.

Tsimplis, M., Woolf, D., Osborn, T., Wakelin, S., Wolf, J., Flather, R., Shaw, A., Woodworth, P., Challenor, P., Blackman, D., et al., 2005. Towards a vulnerability assessment of the UK and northern European coasts: the role of regional climate variability. Philos. Trans. Roy. Soc. London Ser. A: Math. Phys. Eng. Sci. 363 (1831), 1329-1358.

Wahl, T., Haigh, I., Woodworth, P., Albrecht, F., Dillingh, D., Jensen, J., Nicholls, R., Weisse, R., Wöppelmann, G., 2013. Observed mean sea level changes around the North Sea coastline from 1800 to present. Earth Sci. Rev.

Wahl, T., Jensen, J., Frank, T., 2010. On analysing sea level rise in the German Bight since 1844. Nat. Hazards Earth Syst. Sci 10, 171-179. 
Wahl, T., Jensen, J., Frank, T., Haigh, I., 2011. Improved estimates of mean sea level changes in the German Bight over the last 166 years. Ocean Dyn. 61 (5), 701-715.

Wakelin, S., Woodworth, P., Flather, R., Williams, J., 2003. Sea-level dependence on the NAO over the NW European Continental Shelf. Geophys. Res. Lett. $30(7), 1403$.

Willmott, C. J., 1981. On the validation of models. Phys. Geogr. 2 (2), 184194.

Wiltshire, K. H., Manly, B. F., 2004. The warming trend at Helgoland Roads, North Sea: phytoplankton response. Helgoland Mar. Res. 58 (4), 269-273.

Woodworth, P., Flather, R., Williams, J., Wakelin, S., Jevrejeva, S., 2007. The dependence of UK extreme sea levels and storm surges on the North Atlantic Oscillation. Cont. Shelf Res. 27 (7), 935-946.

Woodworth, P., Player, R., 2003. The Permanent Service for Mean Sea Level: An Update to the 21stCentury. J. Coast. Res., 287-295.

Woolf, D., Shaw, A., Tsimplis, M., 2003. The influence of the North Atlantic Oscillation on sea-level variability in the North Atlantic region. Global Atmos. Ocean Syst. 9 (4), 145-167.

Yan, Z., Tsimplis, M., Woolf, D., 2004. Analysis of the relationship between the North Atlantic oscillation and sea-level changes in northwest Europe. Int. J. Climatol. 24 (6), 743-758. 
Table 1: Results of linear regression analysis of winter-mean (JF) anomalies at Helgoland (in the period of 1953-2008) and Den Helder (in the period of 1953-2004) with NAO index . All correlation coefficients are significant at the $95 \%$ level.

\begin{tabular}{lllll}
\hline & \multicolumn{2}{c}{ Helgoland } & \multicolumn{2}{c}{ Den Helder } \\
\hline & Corr. & Sensitivity to NAO & Corr. & Sensitivity to NAO \\
\hline temperature & 0.63 & $0.49^{\circ} \mathrm{C}$ per unit & 0.75 & $0.61^{\circ} \mathrm{C}$ per unit \\
tide gauge SL & 0.66 & $72 \mathrm{~mm}$ per unit & 0.66 & $51 \mathrm{~mm}$ per unit \\
$S L_{t+s}{ }^{\mathrm{a}}$ & 0.71 & $64 \mathrm{~mm}$ per unit & 0.65 & $40 \mathrm{~mm}$ per unit \\
$S L_{3 D}{ }^{\mathrm{b}}$ & 0.69 & $70 \mathrm{~mm}$ per unit & 0.65 & $47 \mathrm{~mm}$ per unit \\
$S L_{\text {ThermoS }}{ }^{\mathrm{c}}$ & 0.63 & $1.0 \mathrm{~mm}$ per unit & 0.75 & $1.0 \mathrm{~mm}$ per unit \\
\hline
\end{tabular}

a represents tide + surge modelled sea level (SL); ${ }^{\mathrm{b}}$ represents $3 \mathrm{D}$ baroclinic modelled sea level. ${ }^{c}$ represents local thermosteric sea level. 


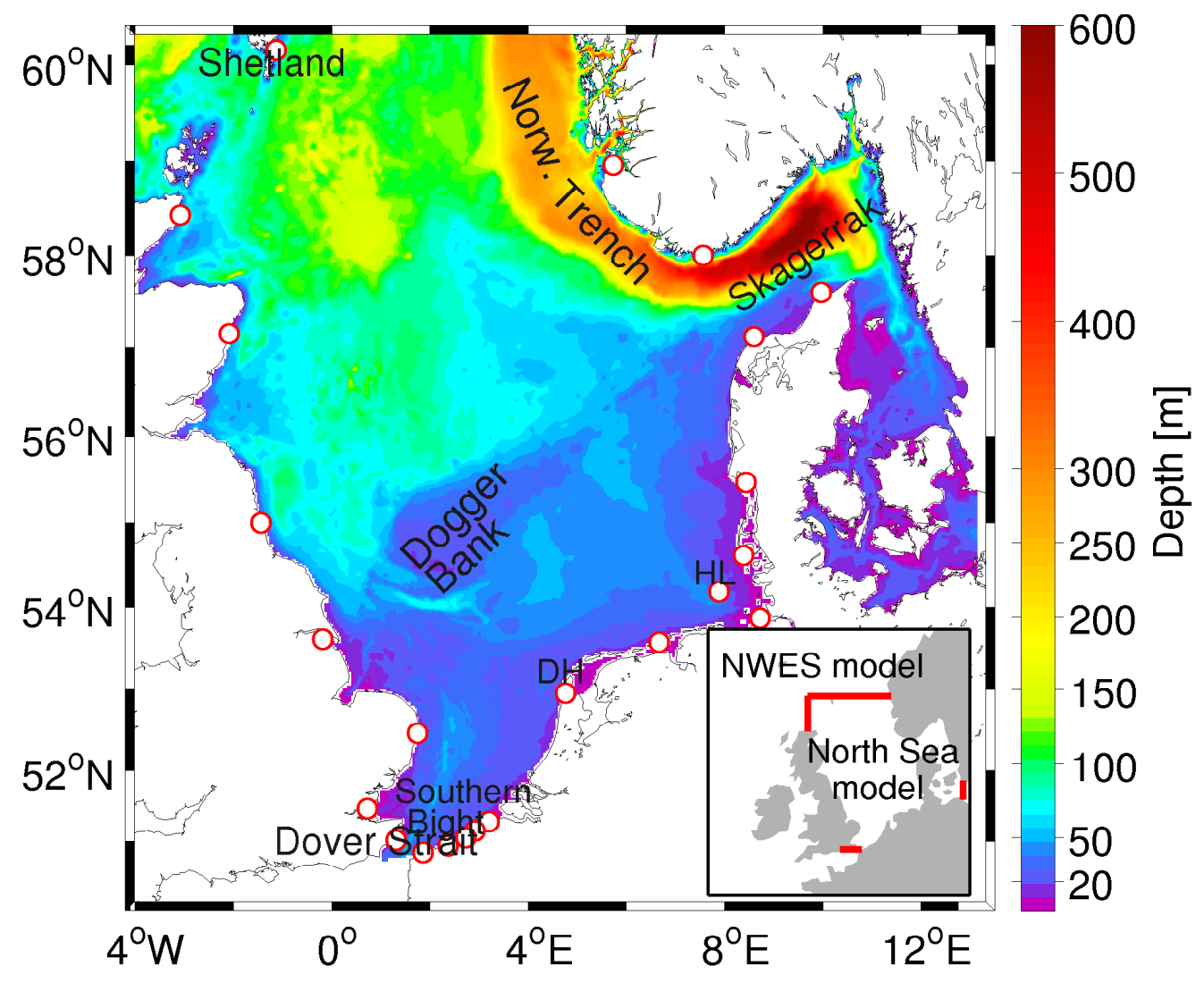

Figure 1: Model domain with model topography for the North Sea region. Insert shows the nested model system, where the large-scale model covers the North-West European Shelf (NWES). The North Sea model is forced by the NWES model at the open boundary. o shows the locations of the tide gauge stations. HL and DH represent, respectively, Helgoland and Den Helder. 

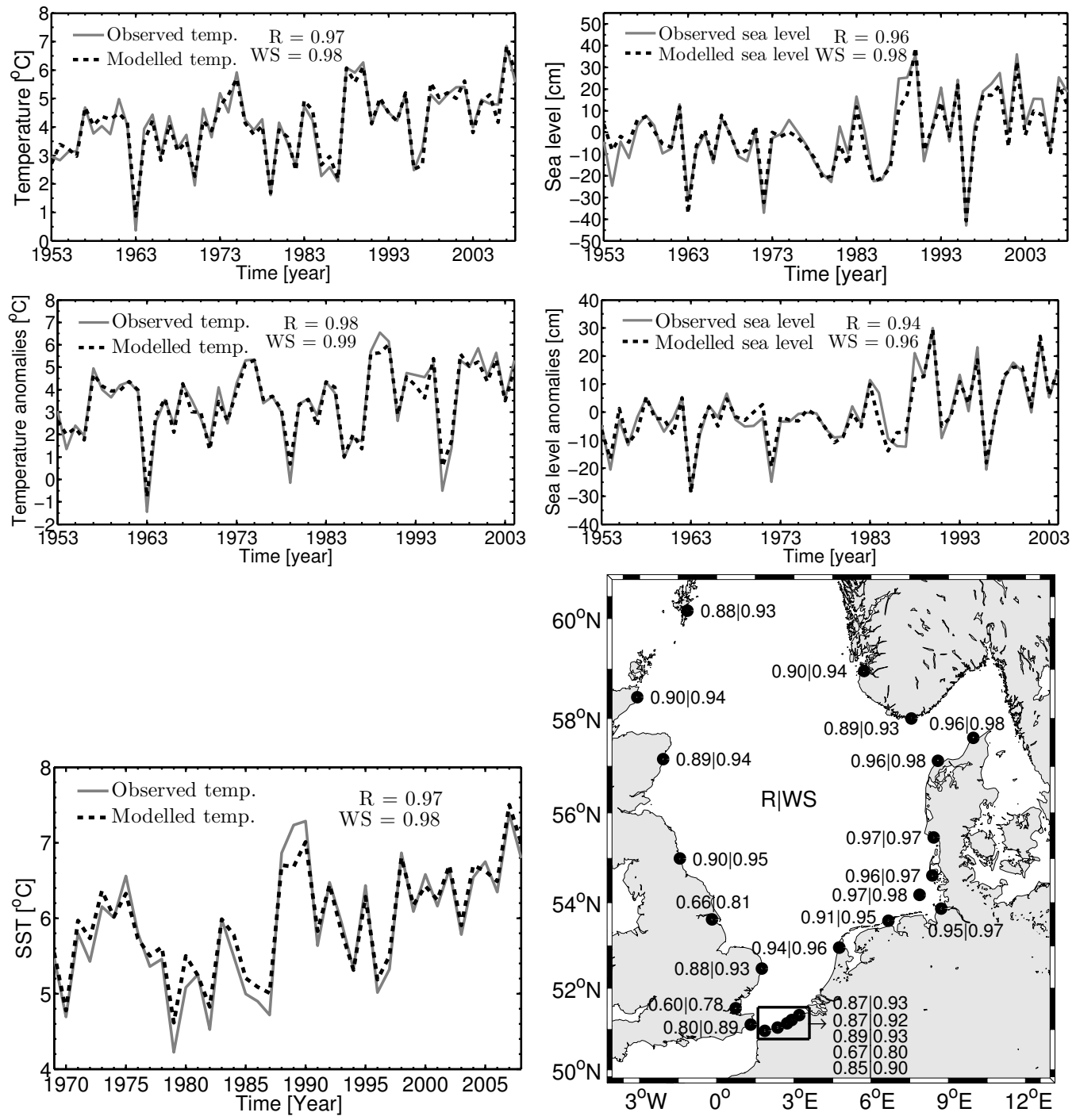

Figure 2: Temperature (a) and sea level (b) comparison between model results and observations for winter-mean (JF) time series during 1953-2008 at Helgoland (up panel) and during 1953-2004 at Den Helder (middle panel). Bottom (left): Domain-averaged SST comparison between model results and observations for winter-mean (JF) time series during 1969-2008. Bottom (right): Comparison between tide gauge and modelled sea level. $R$ and $W S$ represent correlation and Willmott skill (see the text in section 2.1). 


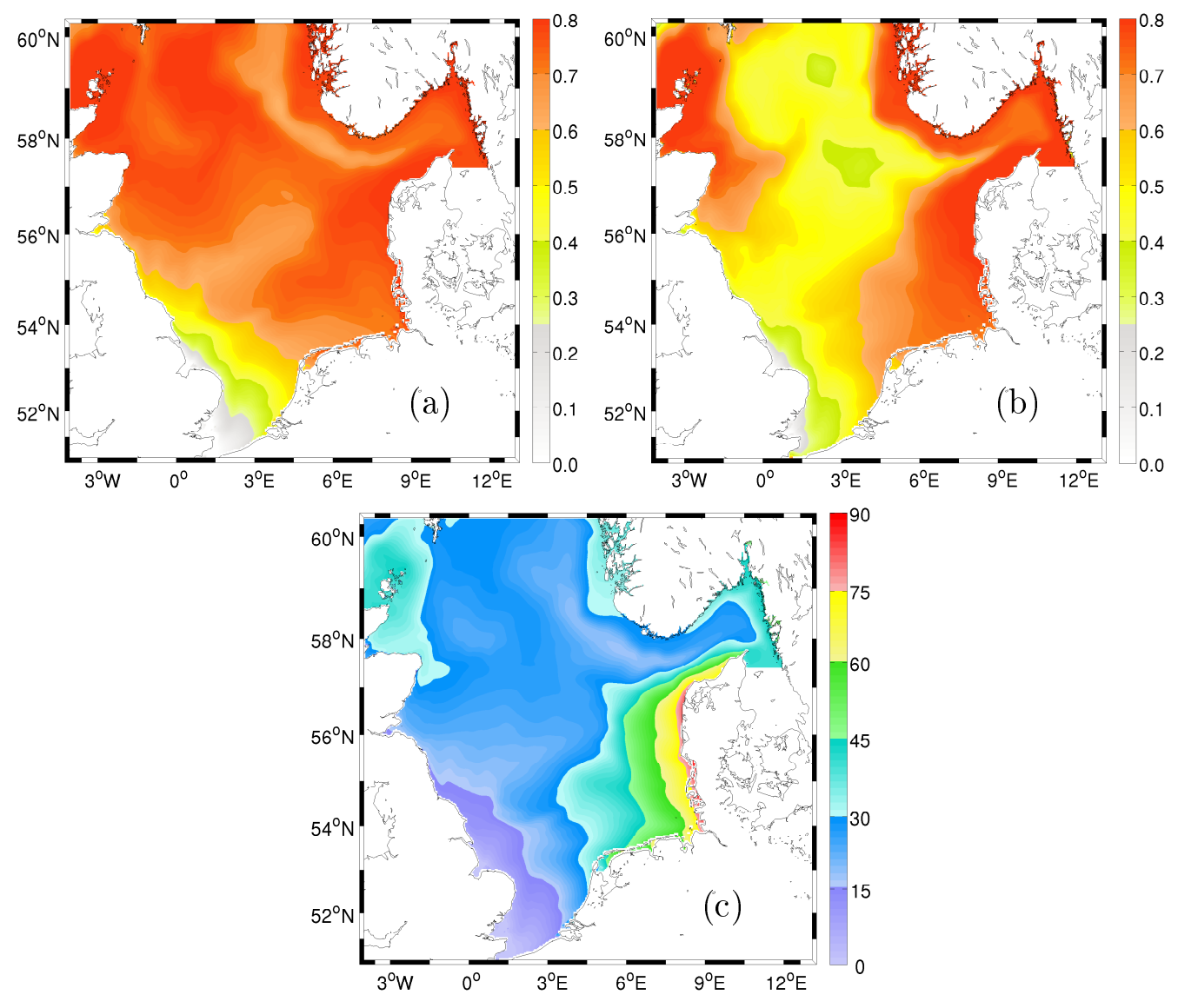

Figure 3: (a) Correlation coefficients between the winter-mean (JF) NAO index and tide+surge modelled sea level $\left(S L_{t+s}\right)$; (b) Correlation coefficients between the wintermean (JF) NAO index and tide+surge modelled sea level without consideration of sea level pressure; (c) Sensitivity of $S L_{t+s}$ to the winter-mean (JF) NAO index (mm per unit NAO). All calculations are over the period of 1953-2010. The sensitivity is analysed with linear regression models between winter-mean sea level and the corresponding winter-mean NAO time series, assuming that sea level/temperature is a linear function of the NAO index (see, text in the third paragraph of Section 2.5). 

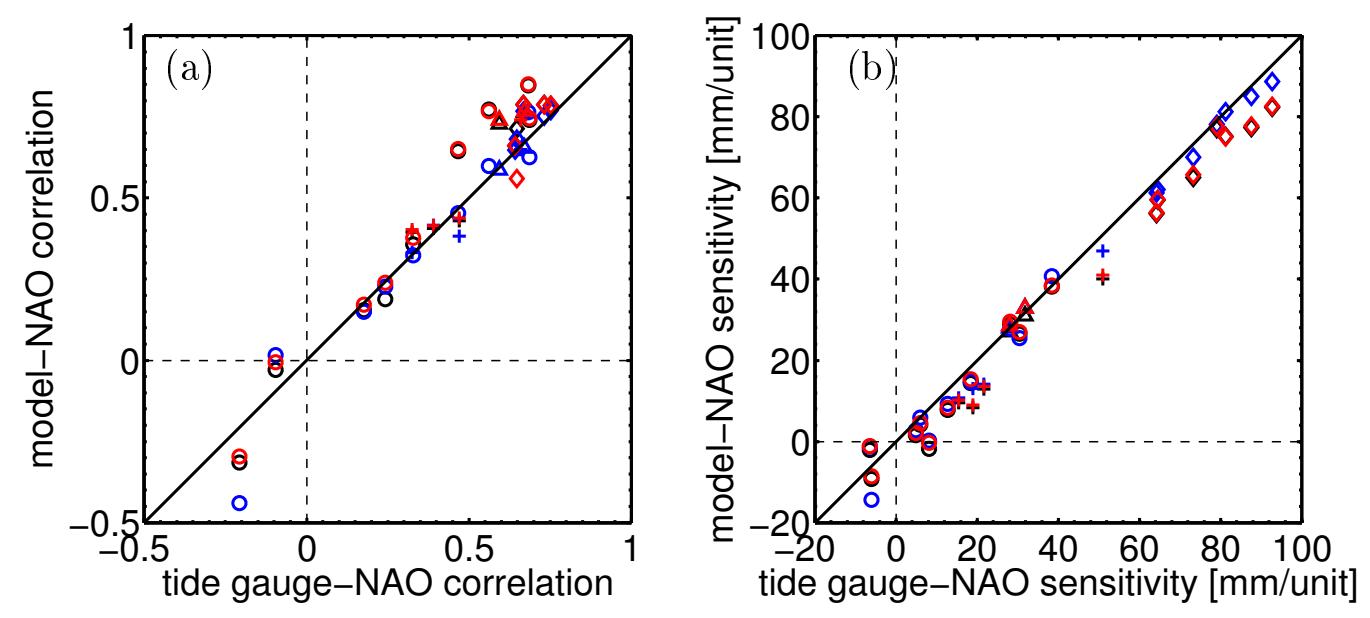

Figure 4: Comparison between the winter-mean (JF) tide gauge observations and $S L_{t+s}$ (in black), $S L_{t+s}+S L_{T h e r m o S}$ (in red), and $S L_{3 D}$ (in blue) over the period of 1953-2008. (a) the correlation coefficients between the NAO index and sea level; (b) sensitivity of sea level to the NAO index (mm per unit NAO index). $\circ \mathrm{UK},+$ France and Belgium, $\diamond$ the Netherlands and Germany and Denmark, $\triangle$ Norway. 


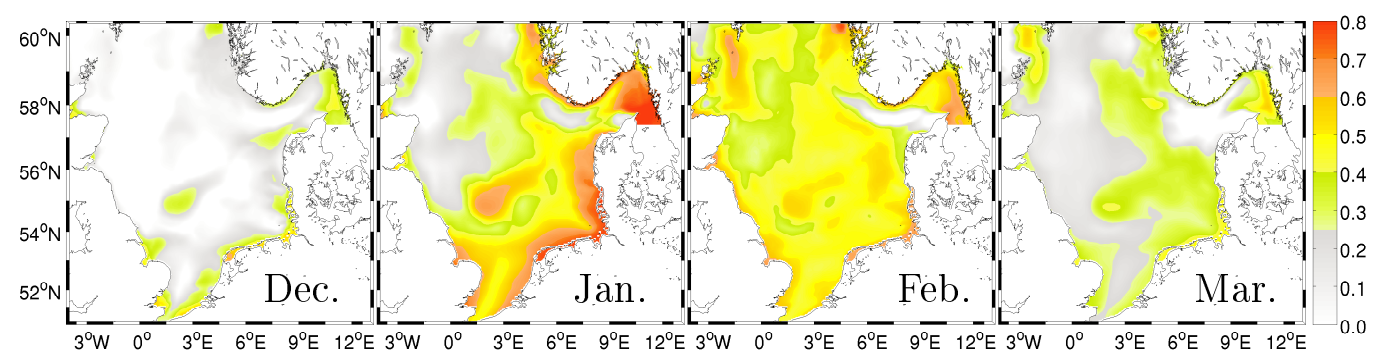

Figure 5: Correlation coefficients between the NAO index and modelled SST during 1953-2010 (for this period the threshold correlation coefficient at the $95 \%$ significance level is about 0.25$)$. 

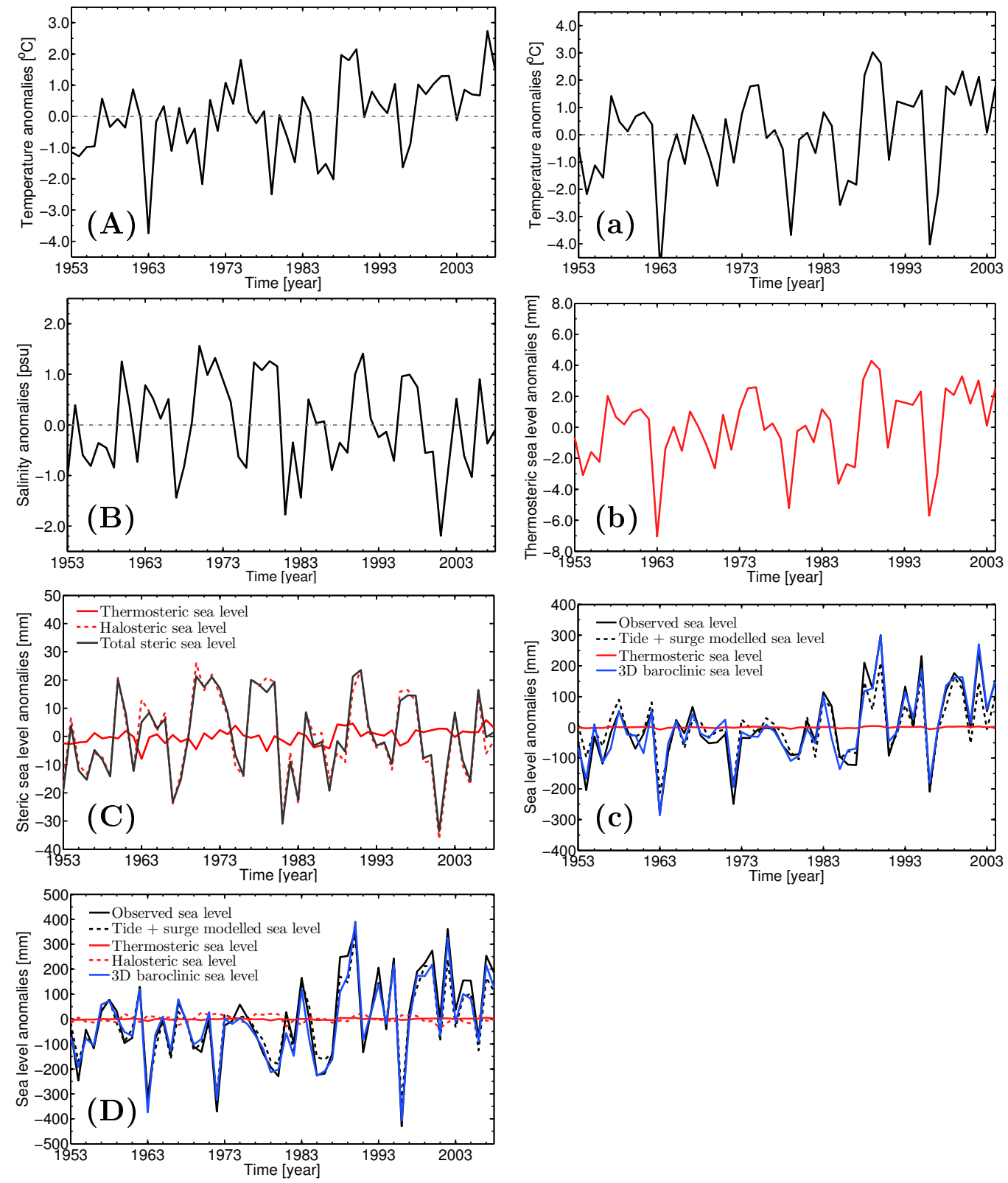

Figure 6: Time series of winter-mean (JF) temperature (A-a), salinity (B), steric sea level (b, C), sea level (c, D) anomalies at Helgoland (Left) and Den Helder (Right), respectively. In (C-c), black solid and dashed lines represent tide gauge and tide+surge modelled sea level, respectively; blue lines show 3D modelled sea level; red solid lines represent thermosteric sea level, which are additionally shown in (D) and (b). Red dashed lines in (C) and (D) shows halosteric sea level. 


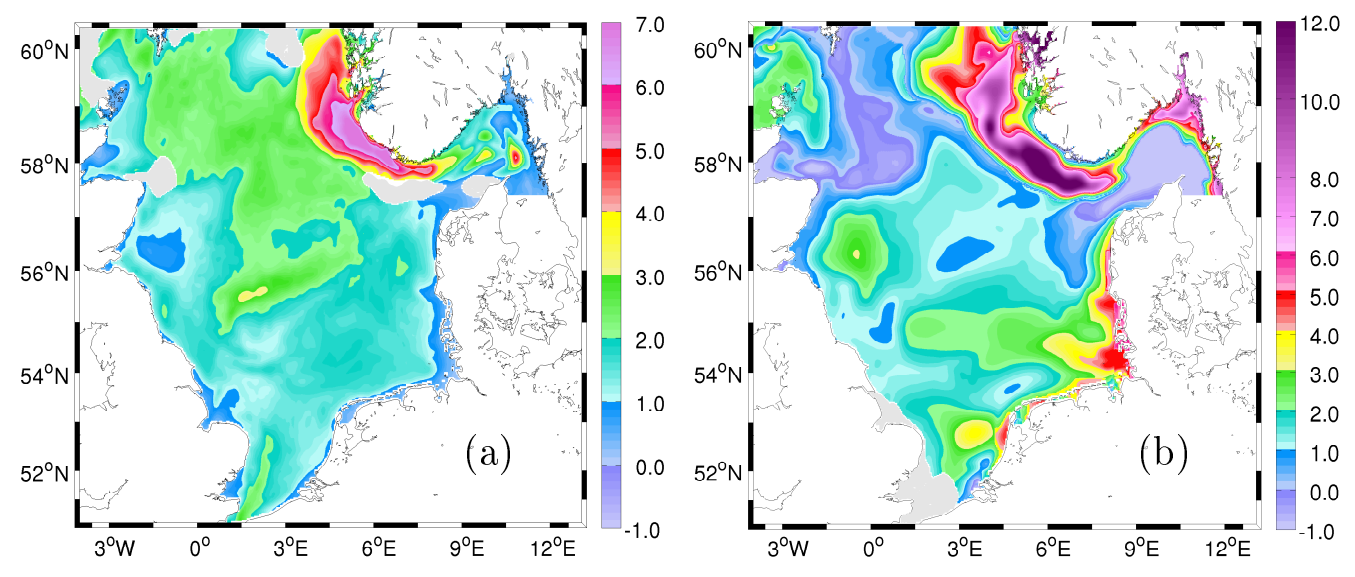

Figure 7: Sensitivity of sea level to NAO winter index during 1953-2010 (mm per unit NAO): (a) of the local thermosteric sea level; (b) of the sea level difference between the baroclinic and the barotropic model results. The areas where the correlation is not statistically significant is shadowed in gray. 